\title{
A UTILIZAÇÃO DOS PRECEDENTES JUDICIAIS COMO UMA INOVAÇÃO PARA A PROMOÇÃO DO ACESSO À JUSTIÇA
}

\section{Matheus Ferreira Bezerra ${ }^{1}$ Rodrigo Andres Jopia Salazar ${ }^{2}$}

Resumo: O presente trabalho representa um estudo sobre a utilização dos precedentes judiciais no direito brasileiro, pautado na doutrina especializado do tema, reconhecendo a inovação decorrente da teoria dos precedentes, sua metodologia própria de construção e o seu impacto sobre o direito ao acesso à justiça, como forma de assegurar uma maior igualdade entre tratamento ao jurisdicionados, a ser dado em casos semelhantes analisados pelo Poder Judiciário, a fim de se estabelecer critérios mais seguros e equitativos de resolução de demandas judiciais.

Palavras-Chave: Precedente judicial; Acesso à justiça; Igualdade

\section{THE USE OF JUDICIAL PRECEDENTS AS AN INNOVATION FOR THE PROMOTION OF ACCESS TO JUSTICE}

Abstract: The present work represents a study on the use of judicial precedents in Brazilian law, based on the specialized doctrine of the subject, recognizing the innovation derived from the theory of precedents, its own construction methodology and its impact on the right to access to justice, as to ensure a greater equality of treatment to the courts, to be given in similar cases analyzed by the Judiciary, in order to establish safer and more equitable criteria for resolving lawsuits.

Keywords: Judicial precedents; access to justice; equality

\section{INTRODUÇÃO}

É possível, sem ferir a garantia do acesso à justiça, tratar os jurisdicionados, frente às decisões judiciais, de forma distinta?

Por muito tempo, dada a existência de premissas associadas a ideologias e momentos históricos anteriores, o problema acima exposto foi resolvido privilegiando a existência do livre convencimento do órgão jurisdicional, relegando a igualdade para um segundo plano.

Ocorre que não se pode mais perder de vista que a garantia do acesso á justiça possui uma dimensão substancial ligada à igualdade dos jurisdicionados frente à definição de

\footnotetext{
${ }^{1}$ Mestre em Direito pela Universidade Federal da Bahia (UFBA). Professor da Universidade do Estado da Bahia (UNEB).Advogado

${ }^{2}$ Mestre em Direito pela Universidade Federal da Bahia. Especialista em Teoria Geral do Processo (UFBA), Especialista em Direito Processual Civil (Faculdade Jorge Amado), Professor Auxiliar da Universidade do Estado da Bahia (UNEB).professor.rodrigosalazar@gmail.br
}

Revista Cidadania e Acesso à Justiça | e-ISSN: 2526-026X | Porto Alegre | v. 4 | n. 2 | p. 61 - 78 | Jul/Dez. 2018 
entendimentos normativos, sendo a igualdade um dos vetores observados na teoria dos precedentes judiciais.

Falar de precedentes e de toda a tecnologia jurídico-processual desenvolvida nos últimos anos no Brasil não é possível sem sua aproximação com a dinâmica peculiar da garantia do acesso à justiça. Primeiro porque não se pode conceber o conteúdo da garantia do acesso à justiça na atualidade desconsiderando o precedente e a força assumida pelas decisões judiciais enquanto fontes normativas. Depois, porque todo o ganho de eficiência e efetividade processual permitida pela utilização (adequada, por óbvio) da técnica do precedente, e sua teoria, reverte em favor da ampliação do acesso à justiça.

Não se pode transitar na análise da garantia de acesso à justiça sem levar em conta que os precedentes e sua teoria permitem a consecução de amplo acesso à justiça de maneira isonômica, segura e eficiente. Por outro lado, o vigor do encantamento dos benefícios da utilização dos precedentes e sua teoria pode esconder os riscos envolvidos na operação de aplicação desse novo instrumental técnico e é exatamente neste meandro que o presente ensaio finca suas bases.

Desta forma, o objetivo da presente pesquisa foi analisar, do ponto de vista dogmático e normativo, a hipótese da existência de ligação entre os precedentes judiciais, a garantia do acesso à justiça e a necessidade de dar tratamento igualitário aos jurisdicionados frente às decisões judiciais.

Para tanto, com uso da metodologia exploratória, o primeiro ponto será a análise do conceito de precedente judicial para, em um segundo momento, analisar a metodologia decisória baseada em precedentes. Como terceiro passo, será demostrada que a igualdade é uma dimensão da garantia do acesso à justiça e que possui uma função normativa importante na adoção de um método decisório baseado em precedentes judiciais. Ao fim serão lançadas as conclusões do presente estudo.

\section{Precedente-decisão}

O precedente judicial costuma ser definido, de forma ampla, como sinônimo de decisão 


\section{A UTILIZAÇÃO DOS PRECEDENTES JUDICIAIS COMO UMA INOVAÇÃO PARA A PROMOÇÃO DO ACESSO À JUSTIÇA}

judicial que pode vir a influenciar na solução de um caso futuro ${ }^{3}$ (BLACK, 2004, p. 3728).

Seguindo essa linha, Zenon Bankowski, Neil Maccormick e Geoffrey Marshall definem o precedente como sendo "qualquer decisão judicial prévia, de qualquer corte, que possua importância para ser aplicada, de forma análoga, em um caso presente" (BANKOWSKI; MACCORMICK; MARSHALL, 1997, p.323).

Com base no mesmo critério, Jeffrey Dobbins entende ser o precedente "qualquer decisão prévia que possua alguma utilidade na decisão de casos posteriores" (DOBBINS, 2010, p.1460).

Por sua vez, ao analisar o precedente por esse prisma, mas não negando a possibilidade de uma abordagem com base na norma presente em um precedente judicial, Fredie Didier Jr, Paula Sarno Braga e Rafael Oliveira entendem que o "precedente é a decisão judicial tomada à luz de um caso concreto, cujo núcleo essencial pode servir como diretriz para o julgamento posterior de casos análogos” (DIDIER JR; BRAGA; OLIVEIRA, 2016, p. 441).

Das conceitualizações acima expostas depreende-se que o conceito de precedente judicial está atrelado ao de decisão judicial, sendo por isso denominado aqui como Precedente-decisão (PD), possuindo dois elementos básicos, que são a existência de uma decisão judicial (dj) e a uma influência prospectiva (ip), já que dirigida para a solução de casos futuros, assim, $P D=d j+i p$. É preciso ressaltar que, nos conceitos examinados, um dos seus elementos, a influência prospectiva (ip), se constitui apenas em influência futura não sendo o mesmo que necessária vinculação futura como se demonstrará mais adiante.

Partindo do mesmo pressuposto: que o precedente judicial é uma decisão, mas tornando o conceito de precedente-decisão mais complexo, já que agrega ao núcleo acima definido outros elementos, Luiz Guilherme Marinoni aceita o precedente judicial como uma decisão, mas ressalta que apenas assumirá a condição de precedente judicial "uma decisão dotada de determinadas características, basicamente a potencialidade de se firmar como paradigma para a orientação dos jurisdicionados e dos magistrados" (MARINONI, 2017, p. 157).

Até aqui o autor parece seguir a mesma linha de entendimento do precedente-decisão que já foi exposto, pois conjuga a existência de uma decisão e sua influência para futuros casos, mas termina por estabelecer a exigência de uma terceira e específica condição para que

\footnotetext{
3 "In a law a precedent is an adjudged case or decision of a court of justice, considered as furnishing a rule or a authority for the determination of an identical or a similar case afterwards, or of a similar question of law". BLACK, Henry Campbell. Black's law dictionary. 8ed, Saint Paul: West, 2004, p. 3728.
}

Revista Cidadania e Acesso à Justiça | e-ISSN: 2526-026X | Porto Alegre | v. 4 | n. 2 | p. 61 - 78 | Jul/Dez. 2018 
se caracterize uma decisão como precedente judicial, qual seja, a existência de um adequado contraditório dos litigantes, resultado de um verdadeiro debate entre as partes (MARINONI, 2017, p. 157-159). Ato contínuo, após defender que a qualidade do contraditório é um elemento do precedente judicial, conclui o autor que "se todo precedente ressai de uma decisão, nem toda decisão constitui um precedente" (MARINONI, 2017, p. 158), deixando bem claro que apenas certas decisões podem ser consideradas como precedentes judiciais. Tem-se, aqui, a seguinte representação: $P D=d j+i p+c$, em que (c) é a existência do adequado contraditório dos litigantes.

Frederick Schauer (SCHAUER, 1946, p. 41.) também entende o precedente judicial como decisão, mas aquela que é dotada de eficácia vinculante. Nesse sentido, não basta que o precedente possa influenciar em uma tomada de decisão futura, mas só se terá caracterizado um precedente quando uma decisão passada vincule decisões futuras, sendo a eficácia vinculante um elemento mais forte que apenas a influência futura. Seguem posicionamento semelhante Evaristo Aragão Santos (SANTOS, 2012, p.142), Lênio Luiz Streck e Georges Abboud que entendem que o precedente só se efetiva como tal quando efetivamente seguido na resolução de casos análogos (STRECK; ABBOUD, 2013, p. 42). Nesse contexto, temos um conceito de precedente-decisão que difere da representação base anterior, descrita por PD $=d j+i p$, pois aqui a representação do Precedente-decisão assume a seguinte forma: $P D=d j$ + IP, sendo IP um elemento novo, em relação aos conceitos anteriores, que é a necessária vinculação normativa em casos futuros.

Ainda que entenda que o precedente judicial é norma jurídica, Hermes Zaneti Jr. também distingue a decisão que pode ser fonte de precedente com base na vinculação necessária, mas agrega outro elemento ao conceito de precedente-decisão, defendendo ser fundamental que a decisão, base do precedente seja qualificada quanto a sua origem. $\mathrm{O}$ autor apenas admite como fonte de precedente judicial a decisão que seja oriunda de cortes superiores (ZENETI JR, 2016, p. 309). Com tal exigência, a representação do precedentedecisão passa a ser PD = DJ + IP, sendo DJ a decisão de cortes superiores.

São todos conceitos bem construídos, aceitos pela doutrina, e que partem de um mesmo prisma que é analisar o precedente judicial como uma decisão, por isso aglutinadas na visão do que seja o Precedente-decisão, mas que não estão imunes a uma mesma crítica-base que consiste em definir conceitualmente o precedente judicial tomando como base uma análise 


\section{A UTILIZAÇÃO DOS PRECEDENTES JUDICIAIS COMO UMA INOVAÇÃO PARA A PROMOÇÃO DO ACESSO À JUSTIÇA}

relacional.

Seja ao afirmar que "precedente é a decisão judicial tomada à luz de um caso concreto, cujo núcleo essencial pode servir como diretriz para o julgamento posterior de casos análogos" (DIDIER JR; BRAGA; OLIVEIRA, 2016, p. 441), ou que "uma decisão dotada de determinadas características, basicamente a potencialidade de se firmar como paradigma para a orientação dos jurisdicionados e dos magistrados" (MARINONI, 2013, p. 215), o que se esta afirmando é que para ser precedente, uma decisão judicial deve se relacionar com outra em uma situação futura.

Tais concepções terminam por limitar a identificação do que seja um precedente apenas no momento de sua utilização, assim, diante de tais construções teóricas, o precedente só poderá ser tido como tal quando venha a ser utilizado no futuro como pauta para uma ação. Nesse raciocínio, o instrumento só pode ser considerado como tal quando estiver sendo utilizado, inexistindo quando não estiver a serviço de uma determinada ação, o que nos parece equivocado.

Em verdade, tais definições descrevem o que vem a ser o método de agir com base em precedente e não a essência do precedente, tratando como se fosse um bloco único o ato de medir e a régua usada para isso, confundem, então, instrumento e método.

Confundir o precedente com o método a que serve leva, ainda, a uma associação indevida entre o conceito de precedente-decisão e alguns de seus possíveis efeitos, como, por exemplo, a sua influência mais ou menos forte (influência prospectiva ou efeito vinculante). Incorrem nesse equívoco as definições conceituais que apenas consideram como precedente judicial a decisão que necessariamente deve ser aplicada em situações futuras semelhantes. Para afastar tal entendimento, visualizar a diferença entre o método e o precedente faz todo o sentido, pois coloca o problema da influência do precedente em seu devido local de análise que é a investigação de como determinado sistema normativo regulamenta internamente o grau de influência do precedente.

A transposição de problemas que se ligam à sua formação procedimental para dentro da definição do que seja o precedente-decisão, como a observância do efetivo contraditório ou à hierarquia do órgão prolator de decisão, também não nos parece ser a melhor opção, posto que são questões que também se relacionam com a análise da regulamentação do método de decidir com base em precedentes judiciais.

Revista Cidadania e Acesso à Justiça | e-ISSN: 2526-026X | Porto Alegre | v. 4 | n. 2 | p. 61 - 78 | Jul/Dez. 2018 
Tais conceitos, ao exigir mais elementos do que a existência de uma decisão para que se tenha o precedente-decisão, seja a possibilidade de influência, a necessária vinculação, o contraditório ou a hierarquia da decisão, trazem para o conceito elementos que se situam em campos exteriores ao precedente-decisão, quais sejam o plano da eficácia e o da pragmática da utilização de um precedente em um caso futuro e, por isso, devem ser depurados.

É preciso, então, separar, nos conceitos de precedente-decisão, aquilo que está além do básico que é simplesmente a existência de uma decisão judicial, pois saber como essa decisão será utilizada, como base para extração de argumento ou de uma norma vinculante, ou ainda se foi a decisão construída em um ambiente caracterizado pelo efetivo contraditório ou por órgãos situados em um determinado grau de hierarquia são, repita-se, questões que dizem mais respeito ao método de aplicação do precedente do que ao próprio precedente em si.

Portanto, conclui-se que o precedente, quando visto como decisão, deve ser entendido apenas e tão somente como a própria decisão, qualquer decisão, assumindo a representação de $\mathrm{PD}=\mathrm{dj}$.

É sob esse contexto da visualização do precedente como uma decisão judicial que se pode afirmar que os precedentes, assim como os enunciados advindos da legislação, textos que precisam ser interpretados, sendo essa interpretação realizada no momento de sua ligação a um caso futuro (BUSTAMANTE, 2012, p. 259).

Definido o conceito de precedente, é necessário identificar o método de decidir que o utiliza como base para a construção de decisões judiciais. Essa análise é útil e necessária, pois permite identificar como a decisão precedente será utilizada na análise de um caso futuro.

\section{O MÉTODO DE DECIDIR COM BASE EM PRECEDENTES}

Decidir é uma forma de agir, razão pela qual é possível, de forma ampla, referenciar os métodos de definição de ações como métodos de definição de decisões. Em um contexto mais estrito existem diferenças, vez que nem todo agir implica em decidir, assim, quando existirem particularidades que diferenciem agir e decidir, será feita a devida referência indicando em que sentido devem ser compreendidos os termos. Feita essa explicação, seguimos na análise do precedente e sua função no contexto decisório.

Conquanto seja possível esboçar um conceito puro de precedente judicial, pensamos que a exata compreensão do mesmo só se dará ao analisar a sua função na construção de

Revista Cidadania e Acesso à Justiça | e-ISSN: 2526-026X | Porto Alegre | v. 4 | n. 2 | p. 61 - 78 | Jul/Dez. 2018 


\section{A UTILIZAÇÃO DOS PRECEDENTES JUDICIAIS COMO UMA INOVAÇÃO PARA A PROMOÇÃO DO ACESSO À JUSTIÇA}

decisões judiciais. É nesse contexto de funcionalidade que podemos descrever o panorama geral do decidir com base em precedentes.

A busca por modos que permitam orientar ações é comum na vida cotidiana, sendo impossível enumerar todas as formas que podem ser utilizadas para esse fim (BOUGE, 1985. p.26-27) ${ }^{4}$, dada a incomensurabilidade (FEYERABEND, p. 349-353) (KHUN, 2006, p. 227) de variáveis possíveis de serem levadas em conta no momento de agir.

Algumas dessas maneiras são bastante usuais e óbvias como, por exemplo, agir segundo a intuição ou por meio de razões pessoais. Seguindo tais critérios é possível decidir vestir uma roupa com base na superstição, ir para um determinado local com base em sentimento religioso ou deixar de praticar uma ação por sentir um pressentimento. Nada impede, ainda, que a opção seja, simplesmente, por não agir, confiando na solução que o acaso trará.

Neste contexto, marcado pela amplitude de opções de parâmetros de ação, existe uma grande possibilidade que mais de uma ação seja considerada como correta, ante os critérios escolhidos, criando um verdadeiro labirinto decisório.

Também é possível criar um método que ajude a pautar ações do agir em geral. Tomase aqui a noção de método como um conjunto de ações dirigidas para um determinado fim, método como um procedimento a ser seguido.

Uma dessas possíveis técnicas decisórias, sendo a que mais interessa ao presente estudo, envolve agir com base no que foi feito no passado, diante de uma situação semelhante (DUXBURY, 2008, p. 1), até porque "aplicar as razões do passado para resolver problemas do presente e do futuro é uma parte básica da razão prática” (MacCOMRICK; SUMMERS,

\footnotetext{
${ }^{4}$ Desta perspectiva, fica clara a existência de práticas metodológicas plurais. Tais práticas no desenvolvimento de uma pesquisa jurídica justificam-se, seja ante uma fragmentação temática bastante evidenciada, seja porque, ao tratar de um conjunto de problemas, cada classe desses problemas requer um método ou técnicas especiais, como ensina Mario Bouge.

${ }^{5}$ Nos referimos à incomensurabilidade como expressão de multiversidade de variáveis possíveis. O termo incomensurabilidade, para Feyerabend, envolve a existência de uma diversidade de teorias científicas, em torno de um mesmo domínio, e que não admitem comparações diretas já que são baseadas em suposições incompatíveis. É, pois, um problema de compatibilidade lógica-teórica dada a existência de teorias construídas com paradigmas distintos. Para Khun, a incomensurabilidade consiste na incomensurabilidade dos paradigmas. Dado que uma revolução científica ocorre quando temos a comunidade científica aceitando um novo paradigma, diferente e incompatível com o anterior, teríamos uma verdadeira mudança de mundo para os cientistas com a modificação dos conceitos, das questões, pressupostos e métodos anteriormente aceitos. O paradigma é tão marcante que determina a forma do mundo dos cientistas que, ao aceitarem paradigmas diferentes, veem "mundos" distintos.
}

Revista Cidadania e Acesso à Justiça | e-ISSN: 2526-026X | Porto Alegre | v. 4 | n. 2 | p. 61 - 78 | Jul/Dez. 2018 
1997, p. 1) ${ }^{6}$. É esse método, que pauta ações presentes com base no que se fez no passado, que aqui se denomina de método de agir com base em precedentes ou, simplesmente, de decidir com base em precedentes.

Assim, é um erro ligar a utilização de precedentes como ferramentas auxiliares para o agir exclusivamente na atividade jurídica. Em verdade, é possível afirmar que o método de ação baseado em precedentes é usualmente utilizado em diversos campos da ação humana, pois assim procede quem leva em conta ações passadas para pautar uma ação presente (SCHAUER, 2015, p. 50). O professor que decide um pedido de correção de prova, pautandose em uma decisão pretérita, tomada ante a um pedido que tratava do mesmo assunto, está construindo sua decisão sobre um precedente e, em última análise, agindo com base em um precedente.

Seja com base em valores de igualdade, coerência, justiça (PERELMAN, 1996) ${ }^{7}$ ou até mesmo de inércia ${ }^{8}$, quando se age com base em precedentes, é nítido que a ação presente se pauta em um juízo valorativo pretérito, sendo uma ação com base retrospectiva. Nesse momento, a ação se pauta no seguinte raciocínio: em um momento passado como se agiu diante dessa mesma situação (BUSTAMANTE, 2012, p. XII )?

Eis, então, um ponto importante: em um método de decisão com base em precedente, existe a exigência que a ação passada seja levada em conta no presente. Ainda que possa ser afastada, ante a constatação da sua impropriedade para servir de parâmetro, a valoração da ação anterior será uma etapa necessária desse método singular de pautar ações.

Desta forma, a conexão entre passado e futuro, que é a marca do decidir com base em precedente, surge por meio de uma análise de ordem relacional, na qual se leva em conta a situação passada, por escolha metodológica, para com isso pautar a ação presente. Inexistindo esse compromisso com o passado, não se age com base em precedente.

Visto por esse ângulo metodológico, pautar uma decisão com base em precedente consiste em conectar presente e passado, sendo o precedente um instrumento para esse método e pode ser definido, simplesmente, como uma ação passada. Cabe ressaltar que o que se exige é que o agente dialogue com o passado, mas não necessariamente que siga o mesmo

\footnotetext{
6 "applying leasons of the past to solve problemens of presente and future is a basic part of pratical reason". Tradução nossa.

${ }^{7}$ Aqui se utiliza o conceito de justiça formal de Peralman.

${ }^{8} \mathrm{~A}$ ideia aqui é que é possível agir com base em precedente simplesmente para não ter que enfrentar o problema novamente.
}

Revista Cidadania e Acesso à Justiça | e-ISSN: 2526-026X | Porto Alegre | v. 4 | n. 2 | p. 61 - 78 |

Jul/Dez. 2018 


\section{A UTILIZAÇÃO DOS PRECEDENTES JUDICIAIS COMO UMA INOVAÇÃO PARA A PROMOÇÃO DO ACESSO À JUSTIÇA}

sentido da ação passada. Não desnatura o método de agir com base em precedentes a possibilidade de que o agente despreze a ação passada, desde que dialogue com a mesma no presente. $\mathrm{O}$ que descaracterizaria o método de ação com base em precedentes seria a inexistência de compromisso que o agente levasse em conta na ação passada. A indiferença com o passado é que desnatura essa forma de ação. Assim, saber se esse evento passado deve ou não influenciar o presente, bem como em que medida isso ocorre, é uma questão ligada ao método e não da essência do instrumento.

Por isso, afirmar que "o precedente é um evento passado que serve de guia para o presente" (DUXBURY, 2008, p. 1.) ${ }^{9}$ é uma afirmação que só pode ser aceita se pautada em uma visão de utilidade do objeto precedente, sob pena de configurar uma confusão entre o instrumento (precedente) e o método (agir com base em precedente).

Ainda que a grande característica do decidir com base em precedentes seja a conexão com o passado, nem tudo que é vivido no passado servirá como precedente cabendo aqui algumas distinções.

A primeira delas consiste em separar a ação com base em precedente da ação que tem como fundamento a experiência. Quando se leva em conta uma experiência passada para tomar uma decisão presente, avalia-se o que se apreendeu naquele momento aplicando-o ao momento presente (DUXBURY, 2008, p. 3) (SCHAUER, 2015, p. 54). Nesse caso, é até possível que a experiência leve à tomada de uma decisão atual que seja o oposto da anterior, justamente porque se aprendeu que não se deve repetir a ação passada. Por exemplo: deixar de tocar em algo incandescente, pois em um momento anterior a experiência levou a uma sensação de dor extrema. Neste caso, a ação passada não será tomada como parâmetro, mas sim a dor que se vivenciou naquele momento.

Ainda se distinguem o precedente e a experiência quanto ao aspecto valorativo da ação passada, sendo essa a principal diferença entre agir com base no primeiro ou nesta outra. Ao se utilizar da experiência o agente se baseia na probabilidade que a situação presente será como a passada e isso já esgota a importância daquela na ação presente (SCHAUER, 2015, p. 54.). Nada impede, inclusive, que a experiência seja desprezada no presente, sem qualquer motivo e não deixará qualquer vestígio na ação. Já quando o método de tomar uma decisão se pauta em um precedente, o valor dado ao passado leva à necessária análise do quanto feito e

\footnotetext{
9 "A precedent is a past event - in law the event is nearly always a decision - which serves as a guide for present action”'Tradução nossa.
}

Revista Cidadania e Acesso à Justiça | e-ISSN: 2526-026X | Porto Alegre | v. 4 | n. 2 | p. 61 - 78 | Jul/Dez. 2018 
da sua relação com a ação presente, pois decidir com base naquele exige, ante situações semelhantes, levar em conta o comportamento anterior.

De igual forma, o fato de alguém decidir estudar em determinado horário, por exemplo, pode formar um padrão, mas visto de maneira isolada, caso esse agir não tenha que ser necessariamente avaliado como um parâmetro futuro, não poderá ser tomada como uma ação tomada com base em precedente ${ }^{10}$. A situação muda, porém, se o agente assumir que é necessário levar em conta o padrão estabelecido para a tomada de futuras decisões, aderindo ao método de agir com base em precedentes.

É a presença do compromisso com o passado que distingue as diversas formas de lidar com atitudes passadas, todas as diferenciações aqui apresentadas são feitas levando em conta esse dado e apenas reafirma esta característica: o decidir com base em precedentes judiciais exige o compromisso com o passado.

Em suma, a ação só pode ser tida como baseada em um precedente, vista do ponto de vista metodológico, quando envolve a identificação do que foi, avaliando sua compatibilidade com o que é, para forçar um diálogo entre o presente e o passado.

Está claro que decidir com base em precedentes, tem clara função de racionalização da escolha de decisões possíveis, tendo como elemento de justificação o que já foi feito no passado diante de uma situação fática semelhante. O passado é o parâmetro necessário desse modo de agir.

Exposto o que significa agir e decidir com base em precedentes, é necessário indicar se, em sistemas jurídicos, a adoção desse método é uma escolha do intérprete ou se existe alguma característica sistêmica que determina que se assuma o compromisso de dialogar com o passado, que é a grande marca dessa metodologia decisória, sendo esse o objeto do item seguinte.

\section{A IGUALDADE COMO BASE NORMATIVA PARA O COMPROMISSO COM O PASSADO E O ACESSO À JUSTIÇA}

\footnotetext{
${ }^{10}$ DUXBURY, Neil. The nature and authority of precedent. Nova York: Cambridge University Press, 2008, p.
} 4.

Revista Cidadania e Acesso à Justiça | e-ISSN: 2526-026X | Porto Alegre | v. 4 | n. 2 | p. 61 - 78 | Jul/Dez. 2018 


\section{A UTILIZAÇÃO DOS PRECEDENTES JUDICIAIS COMO UMA INOVAÇÃO PARA A PROMOÇÃO DO ACESSO À JUSTIÇA}

Ainda que já seja aceita a noção de igualdade no contexto processual, comumente a mesma é abordada levando em conta a necessidade de se garantir tratamento igualitário dos sujeitos processuais e de oportunizar iguais condições de influência na construção da decisão judicial, sendo um valor inerente ao Estado Democrático de Direito (MARINONI, 2017, p. 111).

Dentro da mesma perspectiva de consenso doutrinário, não existe discussão sobre a necessidade de que a igualdade seja analisada em duas dimensões do processo: uma dimensão externa, que garante a igualdade de acesso à jurisdição e outra interna, que garante a igualdade no processo.

A dimensão externa da igualdade processual se concretiza por meio da garantia de acesso uniforme à jurisdição, "vale dizer: a ordem jurídica deve fornecer os meios necessários para que as partes possam chegar ao processo em posição equilibrada" (ABREU, 2015, p. 153). Nessa perspectiva, o acesso ao Judiciário surge como uma decorrência da igualdade material em que todos devem ser tratados de maneira uniforme, na medida das desigualdades, perante e na lei.

Nesse panorama, o principal destinatário de eventuais deveres ligados à igualdade de acesso ao Judiciário é o Estado: seja em sua feição legislativa, seja a jurisdicional, ao cidadão deve ser garantido pelo Estado o acesso à jurisdição, nem que para isso sejam necessárias medidas que outorguem tratamento diferenciado aos jurisdicionados.

A temática do acesso à justiça foi o centro de parte significativa dos estudos processuais produzidos nas décadas de setenta e oitenta do século passado, quando se constatou que era necessário compreender a garantia do acesso à justiça sob duplo enfoque, um formal e outro substancial. Vale, porém, frisar que a análise isolada de um ou outro enfoque não nos permite o real entendimento da garantia de acesso à justiça, o que só ocorre quando se somam as conclusões obtidas por esse duplo viés investigativo.

A acepção formal a define como a necessidade de o Estado garantir procedimentos jurisdicionais, a fim de que os jurisdicionados possam atuar em juízo. É uma preocupação estatal que se traduziria em disponibilizar, a todos e de forma igualitária, um aparato jurisdicional para tão somente garantir o "direito formal do indivíduo agravado de propor ou contestar uma ação" (CAPPELLETTI; GARTH, 1998, p. 8). 
Foi entendimento que marcou o que seria acesso à justiça no Estado Liberal, notadamente nos séculos XVIII e XIX, em que a igualdade era um valor a formatar as preocupações estatais, não se admitindo diferenciações que não fossem baseadas em "razões de ordem biológicas" (MARINONI, 1999, p.26). Nada mais natural do que pensar assim, diante da forma com que se entendiam os direitos nos Estados Liberais burgueses àquela época.

Nesse contexto histórico, os direitos eram analisados de um ponto de vista eminentemente individualista, de modo que deveriam ser tutelados com base nos esforços empreendidos pelos interessados, mas com a mínima intervenção estatal (CAPPELLETTI ; GARTH, 1998, p.4). Influenciado por esse pensamento é que temos o reconhecimento do acesso à justiça como um direito natural, mas que "não necessitava de uma ação do Estado para sua proteção" (BONAVIDES, 2013, p.45), razão pela qual caberia aos interessados a sua efetivação.

Com a passagem do Estado Liberal para o Democrático, a concretização dos direitos, de forma paulatina, passa a ser um vetor a ser perseguido pelo Estado e não só pelos interessados. Essa mudança de orientação permite que se abandone a ideia de igualdade formal e de intervenção mínima estatal para que se adote a concepção de igualdade substancial, entendida essa como "igualdade de oportunidades e, no nosso caso, igualdade de oportunidades de acesso à justiça” (MARINONI, 1999, p.26).

Isso porque a crença que o Estado Jurídico Liberal lograria devolver ao homem a condição de liberdade que o mesmo tivera na sociedade "pré-estatal ou ainda dar a essa liberdade função preponderante" (MARINONI, 1999, p.22), tornando o Estado um mero servo do indivíduo não foi suficiente para responder aos novos anseios sociais.

Em um novo contexto histórico e social, com o Estado Democrático de Direito, a temática do acesso à justiça ganhou novos contornos. Isso porque, sem a devida proteção do Estado, como ocorria no Estado Liberal, a consagração de direitos, muitas vezes até os expressamente consagrados constitucionalmente, se comprovou inócua (SANTOS, 1985, p.125).

Em verdade, essas acepções, longe de serem conflitantes, são complementares e somadas, permitem entender o que é atualmente o núcleo da garantia do acesso à justiça. Desta forma, sob a égide do Estado Democrático, a garantia do acesso à justiça obriga o 


\section{A UTILIZAÇÃO DOS PRECEDENTES JUDICIAIS COMO UMA INOVAÇÃO PARA A PROMOÇÃO DO ACESSO À JUSTIÇA}

Estado a propiciar mecanismos que não só garantam a apresentação de demandas, mas que, sobretudo, permitam condições de se concretizar efetivamente os direitos quando levados à juízo.

Sob a perspectiva da igualdade interna, todos devem receber tratamento uniforme no processo, garantindo-se aos litigantes o que se denomina de igualdade de armas. Nessa dimensão, a preocupação é dar tratamento racional e eficiente à distribuição de oportunidades de exercício de contraditórios aos sujeitos processuais, pois, ainda que o contraditório não ocorra em uma perfeita simetria, a sua efetiva carga nos casos concretos deve ser equitativa, evitando que ocorra um desequilíbrio de oportunidades em desfavor de uma das partes.

É um viés de análise que leva em conta a dinâmica de posições e situações jurídicas titularizadas pelos sujeitos processuais, de forma a que se constate o equilíbrio de suas posições e, por consequência, da carga de contraditório. Desde que se garanta uma situação de harmonia quanto às oportunidades de contraditório, é possível que se dê um tratamento desigual aos sujeitos, sem que isso ofenda a igualdade no processo, confirmando-se, nitidamente, uma preocupação substancial de efetivação à garantia do acesso à justiça.

Não é inútil afirmar que a igualdade no processo também vincula o legislador, impondo-se ao mesmo um dever de previsão de técnicas processuais que sejam idôneas a garantir o equilíbrio processual durante o decurso do processo, "por isso se faz necessária a previsão de regras processuais adequadas (e mesmo adequáveis) às particularidades de cada sujeito do processo" (ABREU, 2015, p. 193).

Unindo-se os dois aspectos da igualdade no processo, surge a necessidade de respeito a um padrão de tratamento harmônico dos sujeitos do processo, tanto no que diz respeito à previsão legislativa de um procedimento como na atividade do juiz e das partes, que garanta um equilíbrio processual.

Desta forma, a missão de buscar e garantir o equilíbrio processual é uma tarefa complexa, envolvendo, de forma complementar, a atividade do legislador e do julgador no iter processual (ABREU, 2015, p. 193).

Ao lado de tais dimensões da igualdade processual, é necessário reconhecer a existência de uma terceira em que a igualdade é avaliada perante as decisões judiciais, ligando-se diretamente com a coerência sistêmica. 
Aurélio Viana e Dierle Nunes indicam que são atributos de um sistema de precedentes a consagração da coerência dos enunciados legais, a estrutura organizacional de emissão de pronunciamentos e a autoridade exercida pela estrutura organizacional dentro do sistema (VIANA; NUNES, 2018, p. 200). Esses autores, nesse particular, apresentam noção muito próxima a que é utilizada nessa dissertação, que conclui que em sistemas normativos, caracterizados pela organização interna complexa, a coerência serve de aferidor sistêmico de validade das normas construídas nas decisões judiciais.

A adoção da coerência, como elemento aglutinador sistêmico, tem como consequência lógica que as decisões devem dar respostas coerentes para questões normativas semelhantes, reforçando a necessidade de que sejam construídas levando em conta os entendimentos normativos passados. $\mathrm{O}$ respeito à coerência, desta forma, implica no reconhecimento de que a igualdade é um valor que deve ser observado também na reconstrução normativa presente nas decisões judiciais.

É preciso esclarecer que adotamos o entendimento de que é a coerência que fundamenta a igualdade e não o contrário. Desta forma, mesmo que inexistisse a possibilidade de se extrair um princípio da igualdade em uma dimensão frente às decisões judiciais, ainda assim, baseado na coerência sistêmica, as respostas às questões normativas dadas pelos tribunais devem tomar como parâmetro o que já foi decidido anteriormente sobre o tema.

Feito esse esclarecimento, pode-se observar que decidir com base em precedentes, em um contexto de coerência, exige que os órgãos jurisdicionais competentes dialoguem com as construções normativas anteriores, baseado na ideia do treat like cases alike, sempre que o contorno fático do caso presente guarde relação de semelhança com aquele em que se originou o precedente. É uma dimensão da igualdade, fundamentada na necessidade de coerência sistêmica, que garante a todos os jurisdicionados um tratamento uniforme na aplicação do direito, fazendo com que a prática da igualdade pelo juiz também envolva o julgamento das questões.

Partindo dessa premissa é possível indicar que a igualdade, como princípio jurídico, só se efetiva em sua carga máxima quando os jurisdicionados são tratados de forma igualitária frente às decisões judiciais.

A igualdade perante as decisões judiciais pode ser alcançada basicamente por três formas distintas e complementares: previsão de técnicas de gestão e reunião de questões 


\section{A UTILIZAÇÃO DOS PRECEDENTES JUDICIAIS COMO UMA INOVAÇÃO PARA A PROMOÇÃO DO ACESSO À JUSTIÇA}

iguais para que sejam dirimidas em um único julgamento; implementação de ritos que permitam a formação de uma tese jurídica que pode ser replicada em processos futuros (ABREU, 2015, p. 218.) e o reconhecimento de que as decisões judiciais devem ser construídas com base em precedentes por respeito à coerência sistêmica.

Boa parte das críticas ao papel dos precedentes, no sistema jurídico brasileiro, são feitas sem levar em conta a necessidade de um tratamento igualitário dos jurisdicionados, frente às decisões judiciais, como uma decorrência da coerência e da organização do direito como um sistema.

Conclui-se que desprestigiar a coerência sistêmica como o elemento que reúne e mantém unidas as normas jurídicas em um sistema, especialmente ao se defender a liberdade decisória ampla e a inexistência de um compromisso com o passado na construção de decisões judiciais, significa contribuir para a inefetividade da garantia ao princípio da igualdade em todas as suas dimensões, inclusive naquela ligada à garantia do acesso à justiça, insuflando, ainda mais, o decisionismo lotérico.

\section{CONCLUSÕES}

Ainda que não seja uma inovação, a construção de decisões judiciais com base em precedente assegura o ideal do tratamento igualitário entre os litigantes.

A construção deste precedente vai além da existência de uma decisão judicial que possa vir a influenciar, em tese, qualquer outro julgado. Trata-se de uma construção paradigmática capaz de enfrentar a raiz de determinado problema jurídico e, por conseguinte, ser utilizado como um método para a resolução de conflitos de casos semelhantes.

Aliás, o método de decisão baseado em precedentes se vale da força de decisão anterior para se conferir um padrão de comportamento, tanto capaz de permitir uma segurança para as novas decisões a serem tomadas, já se estabelecendo a regra a priori, quanto para se garantir a igualdade, posto que, em caso semelhante, haverá decisão semelhante. Trata-se, pois, de uma ponte entre o passado e o presente, em que aquele é o parâmetro para a análise deste.

Neste contexto, o princípio da igualdade, uma vez assegurado pela metodologia da utilização do precedente, permite se realizar outro princípio, qual seja, o acesso á justiça, 
através da uniformização das decisões judiciais, para se conferir um padrão capaz de promover maior harmonização das relações jurídico-processuais.

$\mathrm{Na}$ verdade, o enquadramento isonômico por parte do precedente, que considera dois tempos (passado e presente) para a consagração da metodologia ora analisada, atende à própria exigência de coerência sistêmica, essencial para se conferir maior estabilidade às relações jurídico-processuais, segurança à sociedade, além de permitir, inclusive, uma resposta mais célere em demandas repetitivas.

Neste sentido, a adoção da teoria dos precedentes judiciais no direito brasileiro representa uma verdadeira inovação científica, que supera o paradigma anterior do livre convencimento do juiz, capaz de assegurar maior segurança e estabilidade nas relações jurídico-processuais, ao se estabelecer um parâmetro aos julgamentos, a partir da ratio decidendi proferida por um órgão colegiado em que os direitos constitucionais tenham sido observados.

Em suma: a utilização da teoria dos precedentes pelo direito processual civil brasileiro, reforça o papel das decisões judiciais como fontes do direito, confere ao sistema jurídico uma medida mais aberta para a evolução científica, assegurando que o modelo possa acompanhar a realidade cambiante na busca por um ajuste necessário entre a igualdade formal e material, como forma de se assegurar uma maior efetividade do direito ao acesso à justiça.

\section{REFERÊNCIAS}

BORGES, José Souto Maior. Lançamento Tributário. 2 ed. São Paulo: Malheiros, 1999. BUSTAMANTE, Thomas da Rosa. Teoria do precedente judicial. A justificação e aplicação de regras jurisprudenciais. São Paulo: Noeses, 2012.

BLACK, Henry Campbell. Black's law dictionary. 8ed, Saint Paul: West, 2004

COSTA, Eduardo José da Fonseca. [Comentários ao art. 926]. In: CÂMARA, Helder Moroni, (Coordenador), Código de Processo Civil comentado. São Paulo: Almedina, 2016.

CAMARGO, Luiz Henrique Volpe. A força dos precedentes no moderno processo civil brasileiro. In: WAMBIER, Teresa Arruda Alvim (Coord.). Direito jurisprudencial. São Paulo: RT, 2012.

DIDIER JR., Fredie. Sobre a Teoria Geral do Processo, essa desconhecida. $3^{\mathrm{a}}$ ed. Salvador: Juspodivm, 2016. 
DIDIER JR, Fredie, BRAGA, Paula Sarno, OLIVEIRA, Rafael. Curso de direito processual civil, v.2, 11. Ed. Salvador: Juspodivm, 2016.

DIDIER JR, Fredie; CUNHA, Leonardo Carneiro. Curso de direito processual civil, v.3, 13 a ed. Salvador: Juspodivm, 2016.

DIDIER JR, Fredie [Comentários ao art. 489]. In: CABRAL, Antônio do Passo; CRAMER, Ronaldo (Coordenadores) Comentários ao Novo Código de Processo Civil. Rio de Janeiro: Forense, 2015.

GUASTINI, Riccardo. Das fontes às normas. Edson Bini (trad.). São Paulo: Quartier Latin, 2005.

IRTI, Natalino, L'età della decodificazione, 4a ed. Milano: Giuffré, 1991.

LOPES FILHO, Juraci Mourão. O novo código de processo civil e a sistematização em rede de precedentes judiciais in Precedentes, Coleção Grandes Temas do Novo CPC, vol. 3. DIDIER JR, Fredie; CUNHA, Leonardo Carneiro; ATAÍDE JR, Jaldemiro Rodrigues e BURIL, Lucas (coord). Salvador: JusPodivm, 2015.

MACEDO, Lucas Buril. Precedentes judiciais e o direito processual civil. Salvador: Juspodivm, 2015.

MARINONI, Luiz Guilherme. Precedente Obrigatório. 3. ed. São Paulo: RT, 2013.

MARINONI, Luiz Guilherme [Comentários ao art. 927]. In: WAMBIER, Teresa Arruda Alvim; DIDIER JR, Fredie; TALAMINI, Eduardo; DANTAS, Bruno (Coordenadores) Breves Comentários ao Novo Código de Processo Civil. São Paulo: RT, 2015.

MEDINA, José Miguel Garcia. Direito Processual Civil Moderno. 2a ed. São Paulo: RT, 2016.

MELLO, Sebastian Borges Albuquerque. Direito Penal - Sistemas, Códigos e Microssistemas. São Paulo: Juruá, 2004.

MITIDIERO, Daniel. Fundamentação e precedente - dois discursos a partir da decis ão judicial. Revista de Processo. São Paulo: RT, 2012, n. 206.

NEVES, Daniel Amorim Assumpção. Novo CPC. Código de Processo Civil. Lei 13.105/2015. São Paulo: Método, 2015.

PEIXOTO, Ravi de Medeiros. A posição dos tribunais superiores e a eficácia dos precedentes nas causas repetitivas. Revista Dialética de Direito Processual. São Paulo: Dialética, 201 3, n.119.

PEIXOTO, Ravi. Superação do precedente e segurança jurídica. Salvador: Juspodivm, 2015. 
PEIXOTO, Ravi. Aspectos materiais e processuais da superação de precedentes no direito brasileiro. Em: Precedentes, Coleção Grandes Temas do Novo CPC, vol. 3. DIDIER JR, Fredie; CUNHA, Leonardo Carneiro; ATAÍDE JR, Jaldemiro Rodrigues e BURIL, Lucas (coord). Salvador: JusPodivm, 2015.

SCHAUER, Frederick. Precedente. Em Precedentes. Coleção grandes temas do novo CPC. DIDIER JR, Fredie, CUNHA, Leonardo Carneiro; ATAÍDE JR, Jaldemiro Rodrigues; BURIL, Lucas (coord). Salvador: Juspodivm, 2015.

TARUFFO, Michele. Precedente e jurisprudência. Trad. Chiara de Teffé. Civilistica.com. Rio de Janeiro, a. 3, n. 2, jul.-dez./2014. Disponível em: $<$ http://civilistica.com/precedente-ejurisprudencia/>. Data de acesso. 25 de outubro de 2016.

TEPEDINO, Gustavo. O Código Civil, os chamados microssistemas e Constituição: premissas para uma reforma legislativa. In Problemas de Direito Civil, Gustavo Tepedino (coord.), Rio de Janeiro: Renovar, 2001

VILANOVA, Lourival. O Problema do Objeto da Teoria Geral do Estado. In: Escritos Jurídicos e Filosóficos, T. I. Brasília: Axis Mundi/IBET, 2003

ZENETI JR. Hermes. O valor vinculante dos precedentes. $3^{\text {a }}$ ed. Salvador: Juspodivm, 2016 